\title{
ESTUDIO DE ALGUNAS UNIDADES LINGÜÍSTICAS DESIGNATIVAS (2)'
}

Concepción Otaola Olano

$U N E D$

\section{LOS CRISTIANOS. LA COMUNIDAD CRISTIANA, EL COLECTIVO CRISTIANO, EL SECTOR CRISTIANO, LAS FUERZAS CRISTIANAS, ETC}

El término cristiano es de uso común en Melilla, en esta época, para designar a la comunidad no musulmana (El País, 30-III-86, p. 10), sin embargo, es patente el carácter peculiar de su empleo en estos conflictos, ya que el propio Dudú resalta «debo aclarar que los términos 'cristiano' y 'musulmán' han de entenderse en sentido político, no estrictamente religioso" (Melilla Hoy, 11-XII-85, p. 6). Es más, afirma "cuando hablamos de cristianos jamás lo hacemos faltando al respeto, porque el cristianismo como el islamismo y al igual que la democracia significa justicia, paz e igualdad»r. (Melilla Hoy, 17-VI-86, p. 4).

La negación del carácter religioso en el término cristiano en los conflictos de Melilla es resaltada por los propios musulmanes como Dudú, representante del colectivo musulmán, Tatany, presidente de la Asociación Musulmana de España, (Sur, 30-I-86, p. 19) y Mohamed Ahmed Moh, represen-

' El presente trabajo es la continuación del estudio publicado en la Revista Epos n. ${ }^{\circ}$ VI, pp. 147-175. Su objetivo primordial es el estudio, en la prensa, del «sentido» y "efectividad» de las unidades lingüísticas designativas empleadas en Melilla para designar a las dos comunidades más numerosas, durante la conflictividad resultante de la aplicación de la Ley de Extranjeria.

Así mismo, se hace un breve análisis del contenido semántico predominante en la actualidad de algunas de estas unidades, necesidad impuesta por los resultados obtenidos del anterior propósito. 
tante de la Agrupación de la Comunidad Musulmana de Melilla (Melilla Hoy, 11-VI-86, p. 7).

Las unidades lingüisticas designativas formadas con el término cristiano para referirse al colectivo no musulmán son aceptadas, mayoritariamente, durante el conflicto en Melilla. No obstante, Ismael Medina, articulista de El Alcázar, rechaza esta denominación con los siguientes argumentos:

«Ello debe recelar que el interés político escondido se circunscriba a la creación de un enfrentamiento entre las aviesamente llamadas comunidad musulmana y comunidad cristiana.

Resulta absurdo que ningún partido político acepte esa neta distinción religiosa en un Estado cuya Constitución laicista y antitea ha borrado cualesquiera clasificaciones de tal índole. Es obvio, de otra parte, que carece de objetividad englobar como cristianos a toda una serie de españoles socialistas, comunistas, o de condición pareja, que se declaran agnósticos, cuando menos. Y algo parecido sucede, aunque con menor énfasis, a esos otros españoles metidos en el saco generalizador de los musulmanes) (El Alcázar, 29-VI-86, p. 5) ${ }^{2}$.

En el extremo opuesto resaltamos un artículo firmado por Secondat en Diario 16 (25-VI-86, p. 11) en el que se escribe:

«Y es penoso que se emplee este calificativo "cristiano» a unas gentes que desprecian a sus vecinos, se creen una raza superior y usan la violencia para imponer sus privilegios.

En Melilla no hay cristianos, sino mezquindad».

En la conflictividad existente entre las dos comunidades mayoritarias de Melilla parece retomarse el empleo de cristiano con los valores predominantes en los siglos VIII a XIII, en los que se usaba como calificativo genérico para denominar de manera agrupada a quienes se oponían a los moros. Una vez más en la historia va a echarse mano de la dialéctica musulmanes/ cristianos con todas sus unidades e, incluso, la tan manida moros/cristianos.

A pesar de todo resalta la escasa frecuencia de uso de la unidad colectivo

${ }^{2}$ Si no se indica lo contrario, el subrayado de los textos será siempre nuestro. 
cristiano frente a la gran abundancia de colectivo musulmán y su sentido especial estudiado anteriormente. (Véase Epos,VI, apartado 1.4.)

\section{Musulmanes/CRISTIANOS; MOROS/CRISTIANOS}

Son muy numerosas y variadas las unidades lingüísticas designativas formadas con musulmanes y cristianos. En todas ellas se quiere plasmar una diferenciación entre ambas comunidades, diferenciación que se teñirá de discriminación e incluso racismo y que abocará en una conflictividad. Así queda patente en unas opiniones de Dudú sobre la Ley de Extranjería:

«Y todos los musulmanes tienen derecho a la igualdad jurídica y política con sus conciudadanos [...] eso precisamente [el derecho al voto] es lo que tratan de evitar por todos los medios los partidos cristianos [...] El colectivo dominante cristiano necesita que los musulmanes estén en Melilla [...] constituyen una mano de obra barata, dócil y no especializada".

[...] «Como se ve, la Ley de Extranjería se ajusta a la perfección a los intereses del colectivo cristiano: consagra legalmente la residencia (la integración dicen ellos), de los musulmanes en la ciudad, pero en calidad de extranjeros prorrogables, es decir, se legaliza la desigualdad jurídica y política de los musulmanes en su tierra. [...] mantiene y refuerza su discriminación social en beneficio de la clase dominante cristiana»" (Melilla Hoy, 11-XII-85, p. 6).

Estas designaciones resultan demagógicas para Diego Boscán, articulista de El Alcazár quien dice al respecto:

«[...] ni el discriminar a los musulmanes en beneficio de los cristianos como con toda intención y demagogia dicen Dudú y sus seguidores» (10-XII-85, p. 3).

No obstante, el antagonismo dialéctico terminológico queda recogido 
en la mayor parte de los periódicos como Melilla Hoy, El Sur, Diario 16 y, especialmente, en El Pais, como podemos observar en los textos:

«Alarmante subida del nivel de enfrentamientos y amenazas que, desde hace meses, se registra en la plaza norteafricana entre las comunidades cristiana y musulmana" (29-VII-86, p. 11).

«Los últimos acontecimientos de Melilla, que reproducen una vez más la tensión existente entre el sector cristiano y el colectivo musulmán de la población».

La agresividad arrastra a rememorar antiguos conflictos desenterrando una terminología antigua que sorprende a muchos, como a Mohamed Laarbi «QQuíen ha sacado del baúl la terminología moro-cristiano?» (Melilla Hoy); pero, de hecho, es utilizado en este periodo de tiempo, aunque siempre se niega el carácter religioso del conflicto.

Recordemos que con esta terminología se designaba, en España, a las dos comunidades contendientes, cristianos contra moros, desde el siglo vilI y cuya pugna ocupa enteramente la historia peninsular hasta mediados del siglo XIII, decreciendo en ímpetu hasta la conquista de Granada de 1492.

Quizá uno de los primeros que retomó, en la época actual de Melilla, la terminología moros/cristianos fuese Ricardo Crespo, autor de un libro con ese título que versa sobre la situación de Melilla. Entrevistado sobre el libro y la visión de la ciudad plasmada en el mismo, responde:

«No es una visión muy positiva desde el punto de vista de la dialéctica moro/cristiano, tengo que reconocerlo, pero es objetiva" ( $\mathrm{Me}$ lilla Hoy, 14-XI-85, p. 9).

Esta terminología la adopta El País, especialmente en un editorial titulado «Moros y cristianos» (17-XII-85) en el que afirma:

«[...] la expulsión de los judíos españoles bajo el reinado de los Reyes Católicos y la expulsión de los moriscos bajo el imperio de los Austrias podrian convertirse en la humillante referencia comparativa de esa todavía incoada política de limpieza de sangre y de cristiano viejo que el Gobierno español parece tentado de aplicar en Melilla». 
Terminologia que no parece cuajar en la mayoría de los emisores sino que, por el contrario, la encuentran anticuada.

«Pero el problema es que en Melilla viven dos comunidades. Que empleando un lenguaje anticuado y heredado podriamos calificar de "moros" y "cristianos"” (Melilla Hoy, 13-II-86, p. 3).

En esta misma línea de destacar lo anacrónico de la situación se encuentra el artículo «Moros y cristianos» firmado por Secondat en Diario 16:

"Hiere la sensibilidad la presentación que se hace de los enfrentamientos en Melilla. Son - se dice- unas luchas entre las comunidades cristianas y las comunidades musulmanas. Una guerra de moros y cristianos en 1986».

Aunque se niega que sea una guerra de religión, se ventea una terminología que se asocia con la contienda entre moros y cristianos, como puede ser cruzada, antimoros, Santiago matamoros, etc. que nos hacen introducir estas unidades dentro de la misma red semántica.

Recordemos, una vez más, la postura del Vicario Episcopal de Melilla respecto al empleo de esta terminología. (Véase, Epos, VI, p. 161.)

\section{OTRAS DESIGNACIONES DIFERENCIADORAS DE AMBAS COMUNIDADES}

Existen otras unidades lingüisticas designativas que refieren a estas dos comunidades «separadas por el origen geográfico y por las creencias religiosas" (El Pais, 17-XII-85). Debemos resaltar aquellas en las que la base diferenciadora no resulta la misma a la hora de designar las dos comunidades, mezclándose criterios religiosos, étnicos, de origen, etc. 
"Tras los recientes conflictos entre la población musulmana de Me- lilla y los habitantes de origen peninsular, a raiz de la ley de Extranjeria [...]» (El Pais, 8-XII-85, p. 5).

«[...] y ante la Administración planteamos la reivindicación de la auténtica igualdad jurídica entre trabajadores musulmanes y de etnia europea" (El Pais, 29-VI-86, p. 12).

«No se trata de una guerra de religiones por lo que hasta la denominación de los grupos resulta dificil, moros y españoles» (El Pais, 29-VII-86, p. 11).

En otra ocasión El País diferencia musulmanes melillenses de melillenses de origen europeo (16-XI-86, p. 6). Curiosa y acorde con su ideología es la distinción hecha en El Alcázar entre población de origen marroquí y españoles de origen peninsular (29-VI-86, p. 5). Expresión palmaria de esta mezcla de criterios y consecuente confusionismo es la designación que utiliza Sánchez Dragó para referirse a los musulmanes «todos pertenecen a la raza del Profeta" (Diario 16, 16-II-86, p. 10).

\section{MARRoQuíES-RIFEÑOS}

Prueba evidente de la intencionalidad política en el empleo de las designaciones anteriormente tratadas, como las formadas por mulsulmán, cristiano, etc., la encontramos en el uso de las unidades lingüísticas designativas constituidas con el adjetivo marroquí y su plural que, si bien tiene un índice de frecuencia muy bajo, es significativo su empleo por la época en que se hace así como por sus utilizadores.

En los albores del conflicto de Melilla y antes de consolidarse el empleo de los musulmanes junto con todas las unidades constituidas en torno a este término, El País muestra su indecisión terminológica con unidades como las recogidas en un editorial el día 17-XII-85, p. 10:

«[...] en favor de los melillenses de religión musulmana y de origen marroquí [...] melillenses de origen marroquí [...] la antigua tarjeta de estadística expedida en favor de los musulmanes de Melilla [...] marroquies residentes en Ceuta y Melilla [...]”. 
Con posterioridad, como ya apreciamos en el apartado 1.4. (Epos, VI, p. 167) queda generalizado el empleo de musulmanes y de todas las unidades constituidas con este término, siendo utilizadas por la mayoría de los periódicos. Se exceptúan los articulistas de El Alcázar quienes prefieren las unidades formadas con el término marroquí, como colectivo marroquí, comunidad marroquí ( $E l$ Alcázar, 8-XII-85, p. 10), población de origen marroquí (El Alcázar, 29-VI-86, Ismael Medina).

Esta línea también la sigue en 1990 la revista Época $\left(\right.$ (n. $\left.^{\circ} 207\right)$ que alterna la utilización de musulmanes y marroquíes, refiriéndose con esta última designación a los participantes en la manifestación habida el 22 de noviembre de 1985. En este artículo se plasma claramente la alteridad que implica exclusión del musulmán de la comunidad melillense española con el empleo de melillenses o comunidad española para designar a la población "cristiana", mientras que musulmanes, marroquíes, musulmanes melillenses y comunidad musulmana de Melilla serán las designaciones referidas a los musulmanes residentes en Melilla (Época, 27-II-1990, «Melilla la nueva invasión árabe»).

La preferencia, especialmente en la época, del empleo de estas unidades designativas por parte de la derecha política y, concretamente, la ultraderecha, queda también demostrada en un comunicado de la Unión del Pueblo Melillense que fue duramente contestado en un editorial de Melilla Hoy en el que se dice:

«Por eso resultan lamentables errores o malinformaciones como la contenida en el comunicado de la Unión del Pueblo Melillense del pasado viernes que indica un rechazo a un acuerdo alcanzado por el Gobierno de España y «representantes del colectivo MARROQUí de Melilla».

Es evidente que todos ( $y$ nosotros, con toda nuestra fuerza, entre ellos) deberíamos haber puesto el grito en el cielo si nuestro Gobierno hubiera negociado con representantes del Gobierno marroquí (o de Marruecos) sobre Melilla y a espaldas nuestras o de nuestros representantes. Pero es que lo que nuestro Gobierno ha hecho es oír a unos españoles que representan a unos colectivos que viven en dos ciudades españolas [...]» (16-II-86, p. 1).

Gran significación política tiene el empleo, aunque escaso, de la designación con el término rifeño, pues si bien se reconoce que los musulmanes de Melilla son originarios del Rif, con idioma e historia propios, se destaca su carácter radical e independentista y, consecuentemente, se les considera no deseables en el momento que se estudia, como se desprende del siguiente texto: 
«Tras la reunión de altos responsables del Ministerio del Interior, en Madrid, con los cabecillas rifeños [Dudú y Subaire] representantes de las colonias marroquies en Ceuta y Melilla, las aguas parecen remansarse» (Melilla Hoy, 14-II-86).

Determinados miembros del Gobierno utilizaron, en esa época, unidades designativas formadas por el adjetivo marroquí para referirse a los musulmanes de Melilla, hecho que fue fuertemente contestado por el colectivo.

Así, los dirigentes de «los pueblos musulmanes de Ceuta y Melilla» no comprenden cómo el «ministro [de Interior-Barrionuevo] no distingue aún entre los términos musulmán y marroqui) en un informe que presentaba para someter a estudio del Consejo de Ministros (Sur, 30-XI-85).

También el Director General de Política Interior declara en enero de 1985:

«[...] en cualquier caso - dijo- lo que ha sucedido es el resultado de la absoluta irresponsabilidad de Dudú, que está desinformando insistentemente a la colectividad de origen marroquí) (Diario 16, 29-1-86, p. 5).

Después de las voces levantadas contra el empleo de las unidades designativas formadas con marroquí, el propio colectivo musulmán en su fase promarroquí, es decir, ya en noviembre de 1986, en una asamblea, aprobó una moción en la que se proponía «como buena solución para Melilla, la doble nacionalidad para Marruecos y España, ya que ello solucionaría el problema de muchos marroquíes, españoles y melillenses [...]», declarando a continuación que Melilla era «magrebí, árabe y musulmana». En la manifestación de musulmanes, celebrada el 23 de noviembre de 1986, la autodenominación más frecuente será pueblo musulmán de origen marroquí de Melilla.

A raíz de entonces las designaciones preferidas por los musulmanes de Melilla girarán en torno al término árabe, a pesar de ser ellos originarios de la zona marroquí.

Con el paso del tiempo y ya en 1990 parece extenderse, en la prensa, la designación de marroquí, aunque algunos emisores diferencian claramente los musulmanes (marroquíes residentes en Melilla) de los marroquíes en general. (Véase Epos, VI, p. 167.) 


\section{7. ÁRABE}

En un principio, las reivindicaciones de los musulmanes de Melilla apuntaban a considerarse españoles (Véase Epos, VI, apartado 1.3.), sin embargo, al cabo de un año de conflictos, no dudaron en proclamarse árabes. Veamos este contraste en los siguientes textos:

«Nos viene desde nuestro nacimiento el aire español, de haber estado ligado por completo a la cultura, tradiciones, sentimientos y modo de pensar, actuar y juzgar» (Abderramán Mohamed, Melilla Hoy, 2-XI-86, p. 8).

En el otro extremo, el comunicado emitido al término de una asamblea, celebrada como preparación para la manifestación de noviembre de 1986, reza así:

«El colectivo musulmán de Melilla declara el carácter árabe y musulmán de la ciudad de Melilla y no ponemos ninguna objeción a que se integre cualquier colectivo en el tejido social árabe y musulmán de la ciudad de Melilla.

El colectivo musulmán establecerá contactos y relaciones con todos los pueblos árabes que compartan la identidad árabe de Melilla, mantener buenas relaciones con el pueblo español aunque el pueblo musulmán ha perdido toda confianza en el Gobierno español. [...]

Por una Melilla magrebí, árabe y musulmana. Para establecer estos fines el pueblo musulmán contaría con el apoyo de todos los pueblos árabes que comparten su línea y todas las instituciones democráticas del mundo y especialmente de nuestros hermanos, el pueblo español» (Melilla Hoy, 9-XI-86, p. 4).

Esta reivindicación de «lo árabe» ya despuntó en una asamblea celebrada el 14 de abril de 1986, en la que el líder musulmán pidió que «tanto el chelja, como el árabe sean respetados por el estatuto como única forma de garantizar nuestras tradiciones y cultura». (Sur, 15-IV-86).

Nuevamente se reforzó esta reivindicación con la manifestación del 27 de abril, en la que los niños iban ataviados con trajes típicos árabes y que 
se caracterizó por las continuas expresiones que se hicieron del folklore propio de la cultura árabe y bereber. El mismo Mohamedi Dudú manifestaba en esta ocasión "Tenemos una cultura y tenemos nuestras lenguas, el árabe y el tharnesijht (shelja)" (Melilla Hoy, 27-IV-86).

Estas manifestaciones de Dudú sobre la cultura y lengua árabes se repetirán el 9 de noviembre de 1986:

"Si en los Colegios de Melilla no se da el árabe y no se enseña, opcionalmente, la religión musulmana, si no se habla en árabe y castellano, nuestros hijos no irán a ninguna escuela de ellos (Melilla Hoy, 9-XI-86, p. 4).

Con el fin de apoyar esta reivindicación, Dudú propuso el no comprar en comercios europeos, vestir a la usanza árabe y otras acciones de desobediencia civil.

El punto culminante quedó plasmado en la asamblea preparatoria de la manifestación, como ya hemos visto, y en la misma manifestación del 23 de noviembre de 1986 en la que se proclamaba «por nuestro carácter árabe, musulmán y magrebí».

En el período estudiado se ha observado una ausencia casi total de las unidades designativas formadas con el término árabe, con excepción del periódico Diario 16, en el que esporádicamente encontramos unidades como la propia comunidad árabe de Ceuta o la población de origen árabe en Melilla (Diario 16, 3-XII-85, p. 2 y 14-XI-86, p. 10 respectivamente).

Es de destacar el incremento que se observa en el empleo de unidades lingüísticas formadas con árabe en la última etapa del periodo que analizamos, surgiendo a la luz lo que quizá permanecía latente, pues como afirma un corresponsal de El Pais (Carlos Yardoz, 16-XI-86, p. 6):

«Desde hace año y medio, cuando comenzó a fraguarse la organización de la comunidad musulmana, algunos dirigentes del colectivo no dudaron, en conversaciones privadąs, en destacar que los musulmanes melillenses eran originarios de Marruecos y que en la ciudad debía imperar la cultura árabe y la religión musulmana».

Curiosamente el 29 de enero de 1986, Dudú realizó unas declaraciones criticando al Director General de Política Interior, Rafael de Francisco, 
calificándole de «resentido contra todo lo que huela a árabe». (Diario 16, p. 5) y concretamente, como hombre de «profundos sentimientos antiárabes y antimusulmanes» (Sur, 29-I-86, p. 18).

Acorde con la reivindicación árabe de los hasta entonces llamados musulmanes de Melilla, es la postura de El País, periódico que, tres años más tarde, en unos titulares recogerá «Los árabes de Melilla critican a Dudú en el tercer aniversario de las primeras movilizaciones».

Ahora bien, quizá estemos en condiciones de precisar lo que comporta esta reivindicación árabe de los musulmanes de Melilla que, en contradicción aparente, proclaman "una Melilla magrebi, árabe y musulmana». Y decimos contradicción pues, si nos remontamos a la historia, los pueblos magrebies no serán árabes étnicamente hablando, aunque sí musulmanes de religión.

En efecto, siempre a lo largo de la historia ha existido una clara diferenciación entre los árabes y los magrebíes, aunque como bien afirma $\mathrm{C}$. Cahen $^{3}$ «sin que existiese "racismo" aunque los antiguos árabes estuviesen orgullosos de la pureza (cuando existía) de su sangre».

Remontándonos a los primeros tiempos del imperio árabe, si bien los árabes en el siglo VII se expansionaron con sus conquistas por todo el norte de África, siempre encontraron la resistencia bereber, llegando incluso estos últimos a vencer a los árabes en ocasiones, a pesar de que, como afirma Robert Mantran ${ }^{4}$ entre 705 y 708 se sometieron al Islam las tribus del centro y oeste del Magrib.

En un rápido recorrido histórico constatamos que a partir del siglo $\mathrm{x}$ y más concretamente en el XI, el Islam de esta zona era una realidad bereber, aunque de nuevo serán invadidos por los árabes en siglos posteriores. Queda una vez más resaltada la diferenciación pues, como afirma $C$. Cahen " «es tradicional dividir la historia medieval de África del Norte, a partir de Ibn Jaldūn (hacia 1400), en dos períodos separados por la invasión hilalí, y atribuir a los árabes nómadas toda la responsabilidad de la ruina que contrapone al segundo de ellos, prolongado en la época moderna, con la prosperidad que había caracterizado al primero".

Después de la caída de los almohades, Marruecos sigue siendo más berebere mientras que Túnez más árabe.

Actualmente, los nacionalistas marroquíes ondean la bandera del origen

${ }^{3}$ CAHEN, Claude: El Islam. Siglo veintiuno editores, 1980 (6.a edición) p. 127.

- Mantran, Robert: La Expansión Musulmana (siglos vi al XI). Barcelona, Editorial Labor, 1982, p. 70.

Op. cit., p. 221. 
bereber. Bucetta, secretario del Istiqlal, partido nacionalista marroquí, en sus continuás declaraciones reivindicativas de las ciudades de Ceuta y Melilla, esgrimió, en 1986, el argumento de que los antiguos habitantes de las tierras en las que se enclavan actualmente estas ciudades fueron los que ayudaron a Tarik, bereber, en su invasión en el siglo viII de la Península Ibérica, razón por la que no cabe negar la condición de territorio marroquí a dichas ciudades. Recordemos que la reivindicación de la africanidad de Melilla ya quedó manifiesta por Aomar M. Dudú en enero de 1986 cuando desmitificó la historia de Melilla al negar que los cristianos estuvieran en lo que hoy es Melilla desde 1492 «como mantiene la historia oficial». Por el contrario, afirmó que la presencia cristiana en la actual Melilla adquiere consistencia "cuando nosotros [los musulmanes] ya estábamos aquí) (El Sur, 26-I-86, p. 18). A este deseo de marroquización responde la autodenominación de «los musulmanes de origen marroquí) y la reivindicación del «carácter árabe, musulmán y magrebí» de la manifestación del 23 de noviembre de 1986.

Con posterioridad, más próximo en el tiempo y dentro del mismo contexto, se ha podido detectar en la prensa empleos de árabe no sólo para designar a los musulmanes de Melilla sino también como hiperónimo que engloba a los marroquíes. En el primer caso, nos encontramos con autores como Pablo Castellano que dice:

«[... la actual situación de la minoría árabe no enriquecida que, guste o no, es tratada como lo que de verdad se piensa de ellos, como miembros de una población colonizada" (El País, 9-VIII-90, p. 6).

En este mismo contexto Fernando Schawrtz afirma:

«[...] no puede descartarse que la población árabe de las dos ciudades (Ceuta y Melilla) prefiera seguir disfrutando en el futuro de las ventajas socioeconómicas de la españolidad" (El Pais, 9-VIII-90, p. 7).

De gran significación es el titular «Melilla, la nueva invasión árabe» del artículo aparecido en la revista Época en febrero de 1990.

Testimonios del uso hiperonímico de árabe son los siguientes textos de la prensa contemporánea:

«Es uno de los casi 200 ciudadanos de origen árabe, la mayoría marroquíes, que trabajan clandestinamente en los invernaderos" ( $E l$ Pais, 3-VI-90). 
"[...] es el único lugar que encuentran los árabes que llegan al Ejido» (El Pais, 3-VI-90). [Se trata de inmigrantes marroquies].

En muchas ocasiones, actualmente, los propios ciudadanos marroquíes emplean el término árabe para autodenominarse. Ejemplo:

«[...] a los árabes nos tienen prohibido el paso en la mayoría de los bares y locales públicos» (El Pais, 3-VI-1990, p. 9).

Ante la notoria pluralidad de empleos, no podemos abstenernos de preguntar qué designa el término árabe en general y, concretamente, en las manifestaciones habidas en Melilla durante 1985-86.

Los diccionarios como el D.R.A.E. y la Enciclopedia del idioma no nos clarifican la plurivalencia semántica en el empleo de este término, ya que se limitan a ofrecernos la siguiente definición: "natural de Arabia» y "perteneciente a esta región de Asia». La definición del diccionario de M." Moliner resulta algo más explícita al ampliar el campo designativo a los musulmanes, aunque se refiere a los conquistadores y dominadores de la Edad Media. Dice así la entrada árabe: 1. "se aplica a las personas, al idioma y a las cosas de *Arabia y de los pueblos musulmanes». [...] 2. (id.) *Musulmán. «Se aplica a los individuos de los pueblos procedentes de Asia y África, que, profesando la religión de Mahoma, invadieron, entre otros países, España, y dominaron en ella durante la Edad Media, y a sus cosas; particularmente, a su idioma y literatura y a su arte».

En lo que respecta a los historiadores y hombres de letras en general podemos encontrarnos con una parte importante que habla indistintamente de árabes, musulmanes y moros, como lo atestiguan algunos textos del entorno cultural español.

Ortega y Gasset afirma en su obra España invertebrada ${ }^{6}$ "dado el desconocimiento de la propia historia que padecemos los españoles es oportuno advertir que ni los árabes constituyen un ingrediente esencial en la génesis de nuestra nacionalidad, ni su dominación explica la debilidad del feudalismo peninsular». Parece referirse a la dominación musulmana.

De igual modo la pluralidad designativa se detecta en los escritos de

- España Invertebrada. 1952, p. 110. 
Américo Castro ${ }^{7}$ en los que si bien se aprecia una preferencia por el término moro (casta mora) como reflejo de su extendido empleo en los siglos anteriores al XVI, también emplea indistintamente los términos musulmán y árabe. En determinados pasajes la precisión y restricción del campo designativo puede apreciarse en el empleo de árabe (pp. 14-34-35-193) y musulmán (pp. 14-20-186, etc.) referido al mundo de la cultura, tradición y civilización.

Recurre Américo Castro al empleo hiperonímico de musulmán ${ }^{8}$ para referirse a los «invasores musulmanes (árabes, sirios, beréberes) en al-Andalus» concediendo una significación de aglutinamiento de entidad histórica al término. De nuevo" repite «El que la hueste de los sarracenos estuviese integrada por beréberes, por árabes, por cristianos renegados, o por quienes fuesen, no obstaba para que su fisonomía militar y política apareciese ante todo como mahometana, como gente de la "casa del Islam», dar al-islam, que en ella había encontrado su salvación».

En este sentido de no diferenciación étnica y de aglutinación religiosa y cultural se decantan también historiadores como R. Mantran, C. Cahen y Lévi-Provençal refiriéndose a la historia española. Este último, si bien reconoce la diversidad racial existente en un principio en España durante la dominación musulmana, sin embargo, admite la mezcla étnica sufrida entre las poblaciones andalusies hasta el punto de que «cada vez resultaba más dificil distinguir en ellas los aborigenes de los extraños $\aleph^{10}$. De igual manera C. Cahen " afirma que la población de Al-Andalus estaba compuesta por árabes, bereberes y autóctonos aunque estos últimos, convertidos al Islam, en el s. $\mathrm{x}$ ya no se distinguían de los musulmanes de origen árabe puro. D. y J. Sourde ${ }^{12}$ describen el despedazamiento de la España musulmana en una serie de principados árabes, bereberes y andaluces, los reinos de taifas.

Reconocido el escaso número de los racialmente árabes que entraron en España durante la dominación musulmana, será la forma de vida, la tradición y la cultura de los «musulmanes» las que caerán englobados bajo el término árabe, tal vez debido según Mantran ${ }^{13}$ a la notoria incidencia de los primeros conquistadores árabes, durante el denominado «Imperio árabe», en todos los órdenes de la vida, desde la forma de gobierno a la continuación de las tradiciones literarias de la Arabia pre y protoislámica así como la expansión de la lengua árabe como lengua religiosa y de la ad-

'La Realidad Histórica de España. México, Editorial Porrúa, 1975.

${ }^{8}$ Op. cit., p. 33.

Op. cil., p. 29.

${ }^{10}$ Levi-Provençal, E.: España Musulmana. Madrid, Espasa Calpe, 1982, p. 47.

"Op. cil., p. 222

12 Sourdel, Janine et Dominique: La Civilización Clásica del Islam. Barcelona, Editorial Juventud, p. 94.

${ }^{13}$ Op. cit., p. 27. 
ministración. Así lo atestiguan los múltiples sintagmas como cultura árabe, civilización árabe, etc. A pesar de esta gran influencia, la cultura andalusí, como afirma Muhamad Ábid el Jabri ${ }^{14}$, «no es una simple prolongación de la civilización árabe» sino que podemos hablar, al igual que D. y J. Sourdel ${ }^{15}$, de una brillante civilización típicamente andaluza.

Ciertos historiadores prefieren el sintagma civilización islámica, en vez de civilización árabe, pues consideran que es la religión el lazo indisoluble de la comunidad musulmana varia en grupos étnicos y políticos, aunque la voluntad de arabización había servido, en un principio como fermento de unidad.

De todo lo anteriormente expuesto podemos llegar a la conclusión de que el término árabe ha evolucionado notoriamente en su valor designativo, ampliando considerablemente su campo. Como certeramente ha analizado B. Lewis ${ }^{16}$ el término, en un principio tenía el sentido de "beduino» del desierto, los cuales fueron los propagadores del Islam. Posteriormente, se extendió su aplicación a todos «aquellos que hablaban arábigo, que fuesen miembros auténticos por descendencia de una tribu árabe y los cuales, bien en persona o bien por medio de sus antepasados, procediesen de Arabia". Con las conquistas árabes y la expansión del Islam fueron perdiéndose las tradiciones propiamente árabes dando paso a una sociedad musulmana de costumbres y culturas heterogéneas basadas en los elementos autóctonos que sentaron las bases de lo que vino en llamarse la cultura árabe, siendo la lengua árabe el vehículo de la religión y de la nueva civilización.

La permanencia de la unidad lingüistica árabe como designativa de esta cultura y civilización deriva, probablemente, de la identificación islam-arabismo que erigía a los árabes como únicos poseedores de la fe revelada por Mahoma. Debemos recordar que el Islam no es sólo una religión, sino también una conducta social. De aquí que, en Europa, árabe será toda persona que tenga relación con esa religión y con la cultura árabe.

Por otra parte, constrasta la diferenciación que los historiadores sustentan, como anteriormente hemos observado, entre árabes y bereberes, con la actual consideración de los países del Magreb como países «árabes».

En esta línea sabemos que Marruecos no sólo pertenece a la Organización de la Conferencia Islámica, sino también a la Liga de Países Árabes y a la Unión del Magreb Árabe. En estas dos últimas organizaciones es donde podemos apreciar una vez más el valor hiperonímico del tẻrmino árabe, ya que la Liga Árabe no sólo va a estar constituida por paises árabes

14 Catedrático de Filosofia en la Universidad de Rabat. Declaraciones publicadas en $E l$ Pais, 10-VIII-1990, p. 23.

is Op. cit., p. 93 . p. 180 .

16 En su libro Les arabes dans l'histoire. Apud R. MANTRAN: La Expansión Musulmana, 
propiamente dichos, desde el punto de vista étnico, como Arabia Saudita, sino también por otros pertenecientes al Magreb, como Argelia y Marruecos. Por el contrario, en el acuerdo de adhesión de la Unión del Magreb Árabe queda estipulado que podrá solicitar su integración a la misma todo Estado africano que reúna las características de ser árabe y magrebí. De hecho, pertenecen a esta organización Marruecos, Argelia, Mauritania, Libia y Túnez. También desea incorporarse la denominada «República Árabe Saharahui Democrática».

En este contexto «lo árabe» se levanta como contraposición a la $\mathrm{Co}$ munidad Económica Europea y más ampliamente al mundo occidental, tanto en lo político como en lo económico. Así se detecta en la Liga Árabe a la que pertenecen países como Egipto, Siria, Emiratos Árabes, Jordania, Libia, Túnez, Argelia, Marruecos, Sudán, Mauritania, etc. Estos paises tienen distintos intereses pero parece que, en la actualidad, ha resurgido un cierto fundamentalismo o integrismo religioso en que el Islam es la base de este panarabismo, mas también habría que añadir un mínimo común denominador en coincidencias étnicas, lingüísticas y culturales, pues el islamismo se extendió también a otros paises, como Filipinas, y, sin embargo, no pertenecen a esta Liga Árabe. En efecto, únicamente en el caso de los árabes, que son sólo la quinta parte del total de musulmanes en el mundo, la lengua podría ser considerada un denominador común, aparte de la religión. Finalmente, ciertos intereses políticos y económicos permiten englobar dentro de árabe a toda una serie de países.

Dentro de estos valores significativos tiene explicación la consideración de Marruecos como país árabe (Diario 16, editorial 5-III-86) y «la doble dimensión árabe y musulmana de Marruecos» $(A B C, 24-I X-89$, p. 32) así como la afirmación de Bucetta de que España e Israel son las únicas naciones del mundo que actualmente ocupan territorios de soberanía árabe (Diario 16, 10-II-86, p. 5), refiriéndose, en lo que respecta a España, a Ceuta y Melilla.

En el contexto político-social de Melilla en la época que nos ha servido de base para este estudio, cobran especial sentido las declaraciones contenidas en el comunicado emitido por los musulmanes al término de la asamblea extraordinaria de noviembre de 1986, en el que se proclama el carácter árabe, musulmán y magrebí de la ciudad y se busca una solidaridad panárabe para la defensa de sus reivindicaciones. Resalta la declaración, en esta misma ocasión, formulada por el colectivo musulmán «no ponemos ninguna objeción a que se integre cualquier colectivo en el tejido social árabe y musulmán de la ciudad de Melilla». 


\section{CONCLUSIONES}

Acorde con el doble objetivo propuesto al inicio de este estudio, sucintamente expondremos los resultados obtenidos en nuestro análisis.

A lo largo de estas líneas hemos podido apreciar la ideología e intencionalidad subyacentes en este contexto político social de Melilla y su «efectividad», así como las preferencias de uso según los emisores. Así mismo, hemos analizado el significado designativo de ciertas unidades lingüísticas $y$, tras comprobar su sentido, de acuerdo con la terminología de Coseriu, en los textos concretos, hemos desembocado en una constatación de la plurivalencia designativa de la mayor parte de ellas, hecho que explica el confusionismo en el empleo designativo.

En lo que respecta al contexto en el que se desarrollaron los acontecimientos de Melilla, podemos confirmar la existencia, durante el periodo analizado (1985-86), de una gran riqueza de unidades lingüísticas designativas para referirse a los mismos sujetos históricos. Riqueza resultante no sólo de la creación de algunas unidades especiales, como colectivo musulmán, sino también de la aplicación de unidades ya existentes ampliando su campo designativo.

Destacamos la creación de unidades lingüisticas designativas constituidas en torno al término musulmán que remiten a esa población de origen marroquí, más o menos remoto en el tiempo y puro en la raza, que reside en Melilla de manera en mayor o menor medida arraigada. El término musulmán adquiere un contenido semántico diferente al despojarse de su significado religioso, por el que designaría a cualquier practicante de la religión islámica sea de la raza y cultura que fuese, para cargarse, en este contexto específico que tratamos, de un marcado sentido político y diferenciador de la comunidad musulmana y extranjera en Melilla frente a la cristiana y española. En la última etapa del conflicto vuelve a recuperar su pleno significado religioso en boca de los propios musulmanes al proclamar su carácter árabe, musulmán y magrebi.

Con relación al empleo de unidades designativas como comunidad musulmana, población musulmana, colectividad musulmana, etc., cobra mayor relieve la instauración de colectivo musulmán en cuanto implica unidad en la lucha reivindicativa. De su análisis distribucional se deduce su carácter de agente como sujeto de verbos de acción y como complemento determinante de sustantivos como lucha, reivindicación, etc. Podríamos detectar, en el uso de estas unidades, la necesidad de designación por medio de unidades diferentes de las de uso común, especialmente, de moro, debido a las connotaciones que arrastran en la sociedad española. Significativa es la escasa frecuencia de empleo de colectivo cristiano.

Ponemos de relieve el hecho de que, a pesar de la cotidianidad que parece existir en el uso del término moro en Melilla en esa época, sin embargo, es 
evitado por la "oficialidad», es decir, no es empleado por miembros de la Administración o del Gobierno ni se registra en ningún periódico como terminología habitual en sus artículos informativos, editoriales, etc. No obstante, los propios musulmanes y, concretamente Dudú, lo emplean como unidad proferida por los cristianos, es decir, en discurso referido en el que, por el uso del entrecomillado u otro signo tipográfico diferenciador (cursiva), se aprecia su función enunciativa de marcar la alteridad. Recordemos que el valor despectivo que se observa en el uso de moro, en la actualidad, difiere del sentido concedido antiguamente para referirse a todo mahometano, prescindiendo de razas.

De notoria significación política o ideológica es la preferencia en el empleo de las unidades designativas formadas con musulmán por parte de periódicos como El País, Melilla Hoy y, en menor medida, Diario 16, frente a la elección de unidades formadas con marroquí en el seno de los partidarios de una ideología de derecha o ultraderecha y, concretamente en la prensa, en El Alcázar.

Estas marcadas diferencias se desdibujarán cuando, con el transcurso del tiempo y la evolución del conflicto, los propios musulmanes, en consonancia con su posición promarroquí, abandonen en su autodenominación el empleo de unidades calificadas con el adjetivo melillense o español para sustituirlas por unidades como el pueblo musulmán de origen marroquí de Melilla o musulmanes de origen marroquí.

El conflicto entre la comunidad musulmana y la comunidad cristiana de Melilla, reavivado con motivo de la aplicación de la Ley de Extranjería y expresado también en la dialéctica moros y cristianos de evidente cuño medieval, desembocará en una proclamación, por parte de los musulmanes, de adhesión manifiesta a la cultura y modo de vida árabes.

Una vez más, la elección de determinadas unidades lingüísticas para su empleo en un contexto determinado demuestra el componente ideológico subyacente que repercutirá directamente en el sentido en el texto y «efectividad» así como en la extensión o restricción del campo designativo y su consecuente inclusión o exclusión del "otro», es decir, la alteridad.

La evolución, anteriormente expuesta, de los empleos lingüísticos en este breve periodo de tiempo, ha provocado el análisis más pormenorizado de las unidades musulmán, moro y árabe en sus valores designativos y connotativos, especialmente en la época contemporánea.

Curiosamente hemos hallado un valor hiperonímico en cada una de estas unidades léxicas pero, al mismo tiempo, hemos detectado que no siempre son sinónimas.

En efecto, el empleo de la unidad designativa los musulmanes englobando a diferentes razas, árabes, bereberes, sirios, etc., no sólo tiene su raíz en la identificación de musulmán con quien profesa la religión islámica sino que tiene una significación de aglutinamiento, de entidad histórica. En función 
de adjetivo calificativo de sustantivos como civilización, cultura, etc., es sinónimo de árabe.

Del estudio sintagmático y paradigmático de árabe hemos podido concluir que, aparte de su sentido originario étnico (procedentes de Arabia) y del correcto empleo de esta unidad generalmente en la red semántica de la cultura y civilización (arte, literatura, etc.), actualmente, en el uso común, árabe es un hiperónimo que, basándose en criterios religiosos, a veces integristas, culturales, lingüísticos, políticos y sociales y prescindiendo de diferencias étnicas, incluye también el sentido o sentidos de musulmán, moro, magrebí, bereber, rifeño y marroqui que resultan hipónimos. Estos cuatro últimos términos no figuran en el diccionario como sinónimos de árabe.

Por otra parte, el término moro se empleó durante la Edad Media con un valor hiperonímico, junto a al-árabe, con sentido religioso y sin tener en cuenta las etnias. En la actualidad, al menos en el contexto hispano, tiene el mismo valor hiperonímico que hemos detectado en árabe. No obstante, si bien la unidad moro, está presentada en el diccionario como sinónimo en la entrada léxica árabe, sin embargo, no sucede el proceso inverso, es decir, que no aparece árabe como sinónimo en la entrada moro, a pesar de que, como hemos podido comprobar, árabe, moro y musulmán son utilizados para designar a los habitantes de Arabia y Norte de África que conquistaron, dominaron y habitaron en España durante los siglos VIII al XV.

Las semejanzas y diferencias de los empleos de moro y árabe son notorias. En efecto, si bien en Europa, comúnmente, con árabe se designa, independientemente de sus valores connotativos, a toda persona de tez morena relacionada, en algún modo, con la religión musulmana y la cultura árabe, incluyendo a persas, iraníes, sirios, etc., sin embargo, "nuestros» árabe, es decir, los que habitan el norte de Âfrica, son denominados moros en el mundo hispano. Este término amplía su campo designativo al referirse a todos los «árabes» en el sentido concedido a este último término en su empleo en el resto de Europa.

Atendiendo a los valores connotativos que se detectan en la actualidad, destacamos el empleo de árabe y moro dependiendo de los emisores y del contexto, resultando que estas unidades se cargan de nuevos valores semánticos.

Serán árabes todos los habitantes de los paises del norte y este del continente africano comprendidos entre Marruecos, por el este, y Arabia por el oeste, incluyendo también países situados más al norte como Siria, Irak, etcétera. No se dudará en denominarles árabes siempre que comporten poder y riqueza, mientras que recibirán la denominación de moros cuando se desee plasmar los valores despectivos, en especial en el contexto de subdesarrollo, explotación, colonización, poca limpieza fisica y de actuación, etcétera.

Veamos, a modo de ejemplo, algunos textos recogidos en la prensa actual y que reflejan estos nuevos valores, especialmente en el mundo hispano. 
- «Unos nos llegan en sus aviones o en sus yates. [...] compran bancos, especulan con las grandes inmobiliarias [...]. Por supuesto me estoy refiriendo a los árabes. [...]

Los otros nos llegan hacinados en las cubiertas de los barcos [...] viven en pensiones infectas [...]. Trabajan con salarios inferiores a los establecidos legalmente [...]. Son los moros, los morancos» (A. Martínez Menchén - agosto 1990, p. 23).

En opinión de un árabe y musulmán nacido en El Cairo y corresponsal en España durante veinte años:

"Cuando el moro es productor de petróleo, se experimenta hacia él una mezcla de envidia, respeto y misterio. El que no lo es como los del norte de África, seguirá siendo a sus ojos sólo un personaje raro, exótico, que llora más que canta, y con el que hay que andarse con cuidado" (Baher Kamal, Muy Interesante, núm. 114, p. 9).

Testimonios de estos valores también se encuentran en los textos de Pablo Castellano y F. Schawrtz, presentados anteriormente en la página 226.

Para concluir diremos que otro nuevo valor añadido, en la actualidad, al contenido semántico de árabe es el que se desprende al hablar de mundo árabe en oposición a mundo occidental no sólo en cuanto a cultura y civilización sino también por razones políticas y económicas. Un claro exponente es la llamada Liga Árabe, constituida por una gran variedad de países «árabes» incluidos los del Magreb. 